\title{
Quantifying the Impact of COVID-19 on Cancer Patients: A Technical Report of Patient Experience During the COVID-19 Pandemic at a High-volume Radiation Oncology Proton Center in New York City
}

\author{
Robert H. Press ${ }^{1}$, Shaakir Hasan ${ }^{1}$, Arpit M. Chhabra ${ }^{1}$, J. Isabelle Choi ${ }^{1}$, Charles B. Simone II ${ }^{1}$ \\ 1. Radiation Oncology, New York Proton Center, New York, USA
}

Corresponding author: Robert H. Press, rpress@nyproton.com

\begin{abstract}
The COVID-19 pandemic has rapidly spread across the world and now affects more people within the United States than any other country. New York City has emerged as the epicenter of the outbreak in the United States. Both locally and across the country, there is great concern in our ability to deliver appropriate medical care during this time. Radiation therapy is another essential clinical service that cannot afford to suffer prolonged delays without compromising patient outcomes. Early action and guidance are therefore critical to minimize transmission events and ensure safe and timely delivery of radiation therapy. The New York Proton Center (NYPC) is a high-volume free-standing multi-institutional proton center located in Manhattan. The purpose of this report is to describe the institutional patient experience and quantify the impact of treatment delays and interruptions over the first month of the COVID-19 outbreak. We also quantify the incidence of COVID-19 positive patients on census and provide guidance on proactive institutional policies to mitigate patient risk.
\end{abstract}

Categories: Radiation Oncology, Oncology, Public Health

Keywords: covid-19, radiation oncology, patient safety, new york, covid-19 in cancer patients, corona virus, proton therapy

\section{Introduction}

We commend Dinh et al. for their early and informative work describing the radiation therapy policy and procedural changes of the University of Washington (UW) in the Seattle-Puget Sound region during the initial stages of the U.S. COVID-19 outbreak [1]. Their proactive policies provided vital pre-emptive guidance to our department and radiation oncology departments across the country. After Seattle, New York City became one of the next major cities to be affected and has quickly emerged as the epicenter of the COVID-19 pandemic in the United States, with 76,876 confirmed cases as of April 7, 2020.

Received 04/19/2020

Review began 04/20/2020 Review ended 04/20/2020 Published 04/28/2020

\section{() Copyright 2020}

Press et al. This is an open access article distributed under the terms of the Creative Commons Attribution License CC-BY 4.0., which permits unrestricted use, distribution, and reproduction in any medium, provided the original author and source are credited.
The New York Proton Center (NYPC) is a freestanding facility located in Manhattan. Currently, five NYPCemployed radiation oncologists and 19 partner radiation oncologists from three consortium institutions (Memorial Sloan Kettering Cancer Center, Montefiore Health System, and Mount Sinai Health System) treat 80-85 patients/day. Since the first reported COVID-19 case in New York on March 1, 2020, the center has faced many challenges maintaining safe delivery of patient care. As the impact on radiation oncology patients of the COVID-19 pandemic is yet to be quantified, we describe some of our challenges and institutional policies aimed at mitigating the spread of COVID-19 amongst our patients and detail the proportion of patients affected during the initial one-month interval.

\section{Technical Report}

Similar to the UW, we instituted policies to minimize risks to patients, including providing patient education materials; completing daily symptom screenings of patients and close contacts; implementing rigorous sanitization measures; deferring treatment of indolent diseases; instituting telemedicine appointments, virtual meetings, restricting visitors, spacing-out treatment times, and closing patient waiting rooms. Patients in subacute care or nursing facilities were no longer eligible for treatment until discharged and we utilized hypofractionation to shorten treatment schedules per expert-consensus, when feasible [2-5]. Lastly, we began prospectively monitoring each patient on treatment and those expected to initiate treatment for new symptoms, date of onset, possible sick contacts, and COVID-19 test results.

Based on increasing personnel losses due to illness and the need to optimize safety for all of our patients and staff, we deferred treatment of COVID-19-positive patients. By March 19, 2020, we instituted a new patient policy requiring symptomatic patients to obtain a negative COVID-19 test before treatment could resume/initiate, and COVID-19-positive patients must be serologically cleared prior to resuming. Patients 
with high-risk exposure are immediately quarantined and must either remain asymptomatic for a minimum of 10 days prior to treatment (i.e., two standard deviations of the average incubation period) and/or obtain a negative COVID-19 test, if available. Treatment starts are delayed to accommodate these requirements unless urgent circumstances are present, determined on a case-by-case basis.

Institutional Review Board approval was obtained for the evaluation of the following patient-level data. From March 1, 2020 to March 31, 2020, 137 patients received, or underwent simulation to receive, radiotherapy at NYPC. Of these 137 patients, 15 (11\%) were monitored for concerning symptoms or highrisk exposures (Table 1). Alterations in treatment plans due to COVID-19 workup were necessary in 11 (8\%) patients. The remaining four (3\%) patients were monitored due to high-risk exposures (e.g., same household family member COVID-19 positive) but adequately evaluated and cleared through short-term quarantine, symptom evaluation, and/or negative COVID testing without impacting their treatment course. Of the 11 affected patients, seven were cleared and rescheduled for treatment, resulting in a median delay of seven days (range 2-32 days). Four patients, however, are indefinitely delayed or have stopped treatment entirely, including three confirmed COVID-19 infections in total. Of these three, one patient expired due to COVID19 illness and one has initiated comfort care measures.

\begin{tabular}{|c|c|c|c|c|c|c|c|}
\hline Patient & $\begin{array}{l}\text { Age } \\
\text { (years) }\end{array}$ & Site & $\begin{array}{l}\text { Concurrent } \\
\text { CTX }\end{array}$ & $\begin{array}{l}\text { On- } \\
\text { treatment }\end{array}$ & $\begin{array}{l}\text { Symptoms/Risk } \\
\text { factors }\end{array}$ & Outcome & $\begin{array}{l}\text { Days } \\
\text { missed or } \\
\text { delayed }\end{array}$ \\
\hline 1 & 81 & $\mathrm{HN}$ & No & No & Asymptomatic Elderly & Quarantine delayed treatment start & 19 days \\
\hline 2 & 86 & $\mathrm{HN}$ & No & No & Fever, headache & COVID+ admitted to hospital, patient expired & Indefinitely \\
\hline 3 & 57 & $\mathrm{HN}$ & No & No & Fever & COVID- delayed treatment start & 7 days \\
\hline 4 & 59 & $\mathrm{HN}$ & No & No & $\begin{array}{l}\text { Cough, dyspnea, sore } \\
\text { throat }\end{array}$ & $\begin{array}{l}\text { COVID indeterminate quarantined } 14 \text { days } \\
\text { without symptoms, plan to proceed with } \\
\text { treatment }\end{array}$ & 0 days \\
\hline 5 & 66 & $\mathrm{HN}$ & Yes & Yes & Fever, cough & COVID- treatment interrupted & 5 days \\
\hline 6 & 85 & $\mathrm{HN}$ & No & Yes & Fever, cough, dyspnea & $\begin{array}{l}\text { COVID+ admitted to hospital, comfort care } \\
\text { measures initiated }\end{array}$ & Indefinitely \\
\hline 7 & 65 & $\mathrm{HN}$ & Yes & Yes & Fever, cough & $\begin{array}{l}\text { COVID- admitted for } 4 \text { days, treated for } \\
\text { pneumonia }\end{array}$ & 4 days \\
\hline 8 & 6 & Brain & Yes & No & $\begin{array}{l}\text { Asymptomatic indirect } \\
\text { exposure }\end{array}$ & Quarantine resolved before treatment start & 0 days \\
\hline 9 & 7 & Brain & No & No & $\begin{array}{l}\text { Fever admitted due to } \\
\text { other medical reasons }\end{array}$ & $\begin{array}{l}\text { Family refused COVID testing delayed until } \\
\text { discharged }\end{array}$ & 2 days \\
\hline 10 & 70 & Brain & Yes & No & $\begin{array}{l}\text { Asymptomatic indirect } \\
\text { exposure }\end{array}$ & Quarantine & 0 days \\
\hline 11 & 1 & Sarcoma & Yes & No & $\begin{array}{l}\text { Asymptomatic parents } \\
\text { COVID+ }\end{array}$ & Quarantine delayed treatment start & 32 days \\
\hline 12 & 20 & Sarcoma & Yes & Yes & $\begin{array}{l}\text { Asymptomatic father } \\
\text { is COVID+ }\end{array}$ & Deferred COVID testing treatment interrupted & $\begin{array}{l}\text { Indefinitely } \\
\text { (ended } \\
\text { early) }\end{array}$ \\
\hline 13 & 67 & Thoracic & Yes & Yes & Cough, dyspnea & $\begin{array}{l}\text { COVID+ admitted to hospital, treatment } \\
\text { interrupted }\end{array}$ & Indefinitely \\
\hline 14 & 46 & Breast & No & Yes & $\begin{array}{l}\text { Asymptomatic indirect } \\
\text { exposure }\end{array}$ & Quarantine & 0 days \\
\hline 15 & 67 & Gl & No & No & $\begin{array}{l}\text { Asymptomatic wife is } \\
\text { COVID+ }\end{array}$ & Quarantine delayed treatment start & 20 days \\
\hline
\end{tabular}

TABLE 1: Patient characteristics.

CTX, chemotherapy; HN, head and neck; COVID, Coronavirus disease 2019; GI, gastrointestinal 
The majority of patients who required monitoring had not yet started treatment $(9 / 15,60 \%)$. The most common scenario was the development of new symptoms prior to simulation. Of these patients, all but one has since been cleared and rescheduled, resulting in a median delay of 4.5 days (range $0-32$ days). The one patient not yet cleared was confirmed COVID-19 positive and treatment remains on hold. Of the six patients on-treatment requiring further evaluation (40\%), five suffered treatment interruptions, three of whom are now rescheduled to resume after a median delay of four days (range 0-5 days). Three remain indefinitely delayed, including two who were confirmed COVID-19 positive and one who terminated treatment early with two fractions remaining.

\section{Discussion}

Given the proportion of patients who developed symptoms prior to initiating treatment, our experience supports the recommendation for rigorous screening in advance of treatment initiation as well as between appointments (e.g., when simulation and treatment start are $>1$ week apart). In addition, with increasing reports of asymptomatic transmission, routine inspection of lung imaging on simulation and cone-beam CT images is strongly encouraged [6-7]. Patients on-treatment were less commonly affected, which may be due to greater precautions to self-quarantine. However, on-treatment patients may also be more difficult to assess given ongoing treatment-related side effects. For example, some of the most common COVID-19 symptoms occur frequently among cancer patients receiving radiotherapy, including sore throat, cough, shortness of breath, and fatigue. Given the difficulty assessing patients on-treatment for COVID-19 related symptoms, we recommend close scrutiny of any new or ambiguous complaints and a low-threshold for viral testing.

We also have an average of five to seven pediatric patients on-treatment requiring daily sedation with anesthesia. UW's anesthesia policy included airborne precautions due to reports of aerosol transmission [8]. NYPC instituted a policy on March 30, 2020 requiring COVID-19 testing before simulation, again prior to the first fraction, and weekly thereafter while on-treatment to further maximize safety. For patient comfort, the weekly diagnostic nasal swabs are obtained while the patient is under general anesthesia, typically after treatment is completed each Friday to allow test results to return before the subsequent treatment on Monday.

Lastly, we assessed the utilization and sanitization procedure of our respiratory motion management system, SDX (DYN'R, Miami, FL). Similar to UW and Thomas Jefferson University, we developed a new and stringent disinfecting protocol and encouraged the use of abdominal compression and proton repainting techniques over breath-hold whenever clinically possible [9-10]. NYPC now requires manufacturerrecommended monthly full-system cleaning after every patient use which typically takes 10 min to perform. Prior to the COVID-19 outbreak, NYPC treated on average four SDX cases per day. Over the last two weeks prior to publication, only two patients remain on treatment using SDX and no new cases are currently under treatment planning.

\section{Conclusions}

Despite the early implementation of measures described by the UW radiation oncology department as well as our own highly conservative policies, NYPC still had $11 \%$ of patients affected, including $3 \%$ confirmed positive for COVID-19 within the first month and one patient death. All of the delays at NYPC occurred in the second half of the month, suggesting other cities should expect and prepare for an acceleration of patient events near their projected regional pandemic peak. While most interruptions were of short duration and did not appear clinically meaningful, implementation of these strict policies likely mitigated further patient exposure and more significant treatment delays. We plan to continue to enforce and reassess our policies throughout the pandemic to balance patient safety and optimal treatment delivery.

\section{Additional Information}

\section{Disclosures}

Human subjects: Consent was obtained by all participants in this study. Western Institutional Review Board issued approval WIRB Work Order 1-1293594-1. On April 14, 2020, Western Institutional Review Board (WIRB) approved a request for a waiver of authorization for use and disclosure of protected health information (PHI) for the above-referenced research. This review was conducted through expedited review. Animal subjects: All authors have confirmed that this study did not involve animal subjects or tissue. Conflicts of interest: In compliance with the ICMJE uniform disclosure form, all authors declare the following: Payment/services info: All authors have declared that no financial support was received from any organization for the submitted work. Financial relationships: Charles B. Simone, II declare(s) personal fees from Novocure. Honoraria, travel and lodging. Charles B. Simone, II declare(s) personal fees from Astrazeneca. Consulting. Charles B. Simone, II declare(s) personal fees from Varian Medical Systems. Honoraria, travel and lodging, consulting. Other relationships: All authors have declared that there are no other relationships or activities that could appear to have influenced the submitted work.

\section{References}


1. Dinh T-KT, Halasz LM, Ford E, Rengan R: Radiation therapy in King County, Washington during the COVID19 pandemic: balancing patient care, transmission mitigation and resident training. Adv Radiat Oncol. 2020, 10.1016/j.adro.2020.03.007

2. Zaorsky NG, Yu JB, McBride SM, et al.: Prostate cancer radiation therapy recommendations in response to COVID-19. Adv Radiat Oncol. 2020, 10.1016/j.adro.2020.03.010

3. Al-Rashdan A, Roumeliotis M, Quirk S, et al.: Adapting radiation therapy treatments for breast cancer patients during the COVID-19 pandemic: hypo-fractionation and accelerated partial breast irradiation to address World Health Organization recommendations. Adv Radiat Oncol. 2020, 10.1016/j.adro.2020.03.011

4. Braunstein LZ, Gillespie EF, Hong L, et al.: Breast radiation therapy under COVID-19 pandemic resource constraints -- approaches to defer or shorten treatment from a comprehensive cancer center in the United States. Adv Radiat Oncol. 2020, 10.1016/j.adro.2020.03.013

5. Guckenberger M, Belka C, Bezjak A, et al.: Practice recommendations for lung cancer radiotherapy during the COVID-19 pandemic: an ESTRO-ASTRO consensus statement. Radiother Oncol. 2020, 10.1016/j.radonc.2020.04.001

6. Kimball A, Hatfield KM, Arons M, et al.: Asymptomatic and presymptomatic SARS-CoV-2 infections in residents of a long-term care skilled nursing facility - King County, Washington. Morb Mortal Wkly Rep. 2020, 10.15585/mmwr.mm6913e1

7. Inui S, Fujikawa A, Jitsu M, et al.: Chest CT findings in cases from the cruise ship "Diamond Princess" with coronavirus disease 2019 (COVID-19). Radiol Cardiothorac Imaging. 2020, 2:e200110. 10.1148/ryct.2020200110

8. van Doremalen N, Bushmaker T, Morris DH, et al.: Aerosol and surface stability of SARS-CoV-2 as compared with SARS-CoV-1. N Engl J Med. 2020, 10.1056/NEJMc2004973

9. Song A, Manukian G, Taylor A, et al.: Concerns for active breathing control (ABC) with breast cancer in the era of COVID- 19: maximizing infection control while minimizing heart dose. Adv Radiat Oncol. 2020, 10.1016/j.adro.2020.03.009

10. Lin L, Kang M, Huang S, et al.: Beam-specific planning target volumes incorporating 4D CT for pencil beam scanning proton therapy of thoracic tumors. J Appl Clin Med Phys. 2015, 16:5678. 10.1120/jacmp.v16i6.5678 